\title{
Spinal Vascular Endothelial Growth Factor Induces Phrenic Motor Facilitation via Extracellular Signal-Regulated Kinase and Akt Signaling
}

\author{
Erica A. Dale-Nagle, ${ }^{\star}$ Irawan Satriotomo, ${ }^{*}$ and Gordon S. Mitchell \\ Department of Comparative Biosciences, University of Wisconsin, Madison, Wisconsin 53706
}

\begin{abstract}
Although vascular endothelial growth factor (VEGFA-165) is primarily known for its role in angiogenesis, it also plays important neurotrophic and neuroprotective roles for spinal motor neurons. VEGFA-165 signals by activating its receptor tyrosine kinase VEGF receptor-2 (VEGFR-2). Because another growth/trophic factor that signals via a receptor tyrosine kinase (brain derived neurotrophic factor) elicits a long-lasting facilitation of respiratory motor activity in the phrenic nerve, we tested the hypothesis that VEGFA-165 elicits similar phrenic motor facilitation (pMF). Using immunohistochemistry and retrograde labeling techniques, we demonstrate that VEGFA-165 and VEGFR-2 are expressed in identified phrenic motor neurons. Furthermore, intrathecal VEGFA-165 administration at C4 elicits long-lasting pMF; intraspinal VEGFA-165 increased integrated phrenic nerve burst amplitude for at least 90 min after injection $(53.1 \pm 5.0 \%$ at $90 \mathrm{~min} ; p<0.001)$. Intrathecal VEGFA-165 increased phosphorylation (and presumed activation) of signaling molecules downstream from VEGFR-2 within the phrenic motor nucleus, including ERK ( $1.53 \pm 0.13$ vs $1.0 \pm 0.05$ arbitrary units in control rats; $p<0.05)$ and $\mathrm{Akt}(2.16 \pm 0.41$ vs $1.0 \pm 0.41$ arbitrary units in control rats; $p<0.05)$. VEGF-induced pMF was attenuated by the MEK/ERK inhibitor U0126 [1,4-diamino-2,3-dicyano-1,4-bis(o-aminophenylmercapto)butadiene] and was abolished by the phosphotidinositol 3 kinase/Akt inhibitor LY294002 [2-(4-morpholinyl)-8-phenyl-1(4H)-benzopyran-4-one hydrochloride], demonstrating that ERK mitogen-activated protein kinases and Akt are both required for full expression of VEGF-induced PMF. This is the first report that VEGFA-165 elicits plasticity in any motor system. Furthermore, because VEGFA-165 expression is hypoxia sensitive, it may play a role in respiratory plasticity after prolonged exposures to low oxygen.
\end{abstract}

\section{Introduction}

Plasticity is a hallmark of the respiratory control system, including plasticity in spinal respiratory motor nuclei (Mitchell and Johnson, 2003). Growth and trophic factors play a critical role in many forms of neural plasticity, including respiratory plasticity (Mitchell and Johnson, 2003; Golder, 2008). For example, brainderived neurotrophic factor (BDNF) and activation of its highaffinity receptor tyrosine kinase tropomyosin-related kinase B $(\mathrm{TrkB})$ in the cervical spinal cord are necessary and sufficient for a well-known form of respiratory plasticity, phrenic long-term facilitation (pLTF), after acute intermittent hypoxia (AIH) (BakerHerman et al., 2004). TrkB trans-activation via $\mathrm{G}_{\mathrm{s}}$-protein-coupled metabotropic receptor activation also elicits long-lasting phrenic motor facilitation (Golder et al., 2008), demonstrating that multiple distinct signaling pathways (in this case involving TrkB isoforms) give rise to long-lasting facilitation of phrenic motor

\footnotetext{
Received Jan. 14, 2011; revised March 26, 2011; accepted March 31, 2011.

Author contributions: G.S.M. designed research; E.A.D.-N. and I.S. performed research; E.A.D.-N. and I.S. analyzed data; E.A.D.-N. and I.S. wrote the paper.

This work was supported by NIH Grant NS057778. We thank Dr. S. Mahamed for his custom software, which aided the analysis of neurophysiological recordings.

*E.A.D.-N. and I.S. contributed equally to this work.

Correspondence should be addressed to Gordon S. Mitchell, Department of Comparative Biosciences, University of Wisconsin, 2015 Linden Drive, Madison, WI 53706. E-mail: mitchell@svm.vetmed.wisc.edu.

DOI:10.1523/JNEUROSCI.0239-11.2011

Copyright $\odot 2011$ the authors $\quad 0270-6474 / 11 / 317682-09 \$ 15.00 / 0$
}

output (Dale-Nagle et al., 2010). Here, we use phrenic motor facilitation (pMF) as a general term, including pLTF after acute intermittent hypoxia and other forms induced, for example, by spinal administration of receptor agonists.

TrkB is a receptor tyrosine kinase that signals primarily by activation of extracellular signal-regulated protein kinase (ERK) mitogen-activated protein kinases and/or protein kinase B (Akt) (Reichardt, 2006; Golder, 2008). Intermittent hypoxia-induced pLTF is associated with greater ERK phosphorylation (activation) in the region of the phrenic motor nucleus (Wilkerson and Mitchell, 2009), and pLTF requires ERK (not Akt) activation in its underlying mechanism (M. S. Hoffman and G. S. Mitchell, unpublished observation). In contrast, $\mathrm{pMF}$ after $\mathrm{G}_{\mathrm{s}}$-proteincoupled metabotropic receptor activation is primarily associated with Akt activation (Golder et al., 2008), although full expression of this pMF may also require MEK/ERK activation (M. S. Hoffman and G. S. Mitchell, unpublished observation). Thus, receptor tyrosine kinases, in general, have the capacity to elicit pMF through downstream signaling via ERK, Akt, or both.

Vascular endothelial growth factor (VEGF) is typically thought of for its roles in angiogenesis (Connolly et al., 1989) and cell permeability regulation (Senger et al., 1986). However, a prominent role for VEGF in the CNS has been appreciated in recent years, including neurotrophic and neuroprotective effects on spinal motor neurons (Storkebaum et al., 2004; Góra-Kupilas and Jośko, 2005; Zachary, 2005). 
There are several splice variants or VEGF isoforms and three major receptor subtypes (Robinson and Stringer, 2001). The predominant receptor of the VEGFA-165 isoform is VEGF receptor-2 (VEGFR-2). VEGFA-165 is expressed in spinal motor neurons (Hayashi et al., 1999). Here, we report that VEGFA-165 and, more importantly, VEGFR-2 are expressed in identified phrenic motor neurons. Because VEGFR-2 is a member of the RTK family and signals via ERK and Akt activation (Zachary, 2003), we hypothesized that acute spinal VEGFA-165 (via VEGFR-2) (1) is sufficient to induce pMF similar to acute BDNF administration, (2) will increase phosphorylation of signaling molecules downstream from VEGFR-2 (including ERK and/or Akt) within phrenic motor neurons, and (3) that VEGFA-165-induced pMF requires spinal ERK and Akt activation. For brevity, VEGFA-165 will be referred to only as VEGF throughout.

\section{Materials and Methods}

Experimental animals. Electrophysiology experiments were performed using 3- to 5-month-old adult male Sprague Dawley rats (colony 218A; Harlan). Animals were doubly housed in a controlled environment $(12 \mathrm{~h}$ light/dark cycle, daily humidity and temperature monitoring), with food and water ad libitum. All protocols were approved by The Institutional Animal Care and Use Committee at the University of Wisconsin.

VEGF and VEGFR-2 immunostaining and back-labeling of phrenic motor neurons. Naive rats $(n=5)$ were killed with an overdose of Beuthanasia $(0.3 \mathrm{ml}$, i.p. $)$ and perfused transcardially with ice-cold $0.01 \mathrm{M}$ PBS, $\mathrm{pH} 7.4$, followed by $4 \%$ buffered paraformaldehyde. Cervical spinal cords were excised, postfixed overnight, and cryoprotected in 30\% sucrose at $4^{\circ} \mathrm{C}$ until they sank. Transverse sections $(40 \mu \mathrm{m})$ of $\mathrm{C} 4-\mathrm{C} 5$ ventral horn (including the phrenic motor nucleus) were cut using a freezing microtome (Leica SM 200R). In brief, free-floating sections were washed in $0.1 \mathrm{~m}$ Tris-buffered saline with $0.1 \%$ Triton X-100 (TBS-Tx) (three times for $5 \mathrm{~min}$ ) and incubated in TBS containing $1 \% \mathrm{H}_{2} \mathrm{O}_{2}$ for 30 min. After washing (three times for $5 \mathrm{~min}$ ) in TBS-Tx, tissues were blocked with $5 \%$ normal rabbit serum at room temperature (RT) for 60 $\mathrm{min}$. Staining was performed by incubating sections with goat polyclonal anti-VEGF (1:1000; Sigma-Aldrich) or VEGFR-2 or KDR (kinase insert domain receptor) (1:500; Sigma-Aldrich) at $4^{\circ} \mathrm{C}$ overnight. Both VEGF and VEGFR-2 antibodies are widely used, and their specificity has been tested for their blocking capacities (Castilla et al., 2004; Sakao et al., 2007; Smadja et al., 2007; Yamashita, 2007). The sections were washed in TBS-Tx and incubated in biotinylated secondary rabbit anti-goat antibody (1:1000; Vector Laboratories). Conjugation with avidin-biotin complex (Vecstatin Elite ABC kit; Vector Laboratories) was followed by visualization with 3,3'-diaminobenzidine-hydrogen peroxidase (DAB) (Vector Laboratories) according to the instructions of the manufacturer. Sections were then washed in TBS, placed on gelatin-coated slides, dried, dehydrated in a graded alcohol series, then cleared with xylenes, and mounted with Eukitt medium.

To localize VEGF and VEGFR-2 in phrenic motor neurons, freefloating sections from cholera toxin B fragment (CtB)-injected rats (see retrograde labeling protocol below) were washed in TBS-Tx (three times for $5 \mathrm{~min}$ ) and then blocked with 5\% normal donkey serum (NDS) at RT for $60 \mathrm{~min}$. Staining was performed by incubating sections with either rabbit polyclonal anti-VEGF (A-20; 1:200; Santa Cruz Biotechnology) or mouse VEGFR-2 (V3003; 1:200; Sigma-Aldrich) with anti-CtB antibody (non-denatured cholera toxin B; goat polyclonal; 1:10,000; Calbiochem) at $4^{\circ} \mathrm{C}$ overnight. The sections were washed in TBS-Tx (three times for 5 $\mathrm{min}$ ) and incubated in conjugated donkey anti-rabbit green fluorescent Alexa Fluor-488 (1:500; Invitrogen) or donkey anti-mouse green fluorescent Alexa Fluor-488 (1:500; Invitrogen) and donkey anti-goat red fluorescent Alexa Fluor-594 (1:500; Invitrogen). Stained tissues were mounted under glass using anti-fade solution (Prolong Gold anti-fade reagent; Invitrogen). All images were captured and analyzed with a digital camera (Qcapture Pro 6.0; QImaging). The final photomicrographs were created with Adobe Photoshop software (Adobe Systems). All images presented in the figures received equivalent adjustments to tone, scale, gamma, and sharpness. All semiquantitative analysis (see below) was performed before making any adjustments for tone, gamma, or sharpness and was not blinded. Sections incubated without primary or secondary antibodies served as negative controls.

Retrograde labeling of phrenic motor neurons. To localize phrenic motor neurons, 10 rats were used for retrograde labeling with cholera toxin $\mathrm{B}$ subunit by intrapleural injection (Mantilla et al., 2009). Anesthesia was induced in a closed chamber with isoflurane and maintained via nose cone ( $1.5 \%$ isoflurane in $100 \%$ oxygen). Using a $25 \mu$ l Hamilton syringe and a custom-made needle $(6 \mathrm{~mm}, 23$ gauge, semi-blunt so as not to puncture the lung), $25 \mu \mathrm{l}$ of $0.5 \%$ cholera toxin B subunit (List Biological Laboratories) in $0.9 \%$ sterile saline was injected transcutaneously into the thoracic cavity on each side (6 mm deep, fifth intercostal space). Animals were monitored closely for any signs of respiratory compromise, but none were evident in this study. Three days after surgery, the rats were anesthetized and were prepared for intrathecal injections of VEGF or vehicle (see below).

Intrathecal VEGF injections. Anesthesia was induced in a closed chamber with isoflurane and maintained using a nose cone. Rats were then tracheotomized and pump ventilated $(2.5 \mathrm{ml}$; Rodent Ventilator, model 683; Harvard Apparatus). Isoflurane anesthesia continued via the ventilator for the duration of surgical preparations (3.5\% isoflurane in $50 \%$ $\mathrm{O}_{2}$ ). After surgery was complete, rats were slowly converted to urethane anesthesia $(1.8 \mathrm{~g} / \mathrm{kg})$ via a tail vein catheter. To mimic the surgical preparation of the electrophysiology experiments (see below), bilateral vagotomy was performed, the femoral artery was tied off, and phrenic and hypoglossal nerves were dissected and transected. A C2 laminectomy and durotomy were performed to allow placement of an intrathecal silicone catheter (2 French; Access Technologies), with the tip located on the dorsal aspect of the $\mathrm{C} 4$ spinal segment. Rats were paralyzed with pancuronium bromide $(2.5 \mathrm{mg} / \mathrm{kg}$, i.v.). Body temperature was measured with a rectal probe (Traceable; Thermo Fisher Scientific) and maintained within $1-2^{\circ} \mathrm{C}$ of initial measurement using a custom, temperature-controlled surgical table. End-tidal $\mathrm{CO}_{2}$ was measured with a flow-through capnograph with sufficient response time to measure end-tidal $\mathrm{CO}_{2}$ in rats (Capnogard; Novemetrix). Partial pressure end-tidal $\mathrm{CO}_{2}$ was maintained between 41 and $44 \mathrm{mmHg}$. Rats were intrathecally injected with $10 \mu \mathrm{l}$ of either VEGF (recombinant human; $100 \mathrm{ng}$; R \& D Systems) dissolved in $0.1 \%$ bovine serum albumen (BSA) and artificial CSF (aCSF) (in mm: $120 \mathrm{NaCl}, 3 \mathrm{KCl}, 2$ $\mathrm{CaCl}, 2 \mathrm{MgCl}, 23 \mathrm{NaHCO}_{3}$, and 10 glucose bubbled with $\mathrm{CO}_{2}$ ) or vehicle $(0.1 \% \mathrm{BSA}$ in aCSF). After $15 \mathrm{~min}$, rats were perfused and fixed for phosphoERK and phospho-Akt immunohistochemistry.

Phospho-ERK, phospho-Akt, and cholera toxin subunit B immunostaining. To identify phosphorylation of ERK and Akt proteins in the phrenic motor nucleus after intrathecal VEGF, C4-C5 spinal tissues from CtBinjected rats were blocked in NDS for $60 \mathrm{~min}$ and then incubated in phospho-ERK (1:500; Cell Signaling Technology) or phospho-Akt antibodies (1:500; Cell Signaling Technology) at $4^{\circ} \mathrm{C}$ overnight. The sections were washed in TBS-Tx and incubated in biotinylated secondary donkey anti-rabbit antibody (1:1000; Jackson ImmunoResearch). Conjugation with avidin-biotin complex (Vecstatin Elite ABC kit; Vector Laboratories) was followed by visualization with $\mathrm{DAB}$ (Vector Laboratories) with nickel according to the instructions of the manufacturer. After washing with TBS-Tx (three times for $5 \mathrm{~min}$ ), tissues were labeled with anti-CtB antibody (non-denatured CtB; goat polyclonal; 1:10,000; Calbiochem) overnight. The tissues were then incubated in conjugated donkey antigoat red fluorescent Alexa Fluor-495 (1:500; Invitrogen) at room temperature for $60 \mathrm{~min}$ to visualize $\mathrm{CtB}$ staining. Stained tissues were mounted under glass using anti-fade solution (Prolong Gold anti-fade reagent; Invitrogen). Phospho-ERK and phospho-Akt protein expression (brown) were examined in CtB-back-labeled phrenic motor neurons (red) with an epifluorescence microscope (Nikon).

Quantification and analysis of photomicrographs. Four sections from each animal at the C4-C5 segmental level were used for immunohistochemical analyses. Phrenic motor neurons were identified as a cluster of large, fluorescing neurons in the mediolateral C4 ventral horn (Boulenguez et al., 2007; Mantilla et al., 2009). Digital photomicrographs of immunoreactive labeling in the region of the phrenic motor nucleus were taken with the $20 \times$ objective lens (Qcapture Pro 6.0; QImaging). Densi- 
tometry was performed by circumscribing the phrenic motor nucleus based on CtB labeling and determining the intensity of phospho-ERK and phospho-Akt immunostaining using NIH ImageJ software (http://rsb.info.nih.gov/ij). Images were converted to eight-bit resolution, and the threshold was set between 120 and 160 during all analyses. The optical density (OD) was measured within circumscribed phrenic motor neurons and expressed as an average OD per unit area for each individual cell. For each cell, the OD of phospho-ERK and phospho-Akt immunoreactivity was expressed as a fraction of the average OD of all cells in vehicle-treated rats. Thus, the mean OD in control rats is expected to be 1.0 , with a variance that reflects variations among cells in this group. In VEGF-treated rats, the OD was expressed as a ratio to the average of vehicletreated cells. This normalized OD served as a measure of relative protein concentration of phospho-ERK and phospho-Akt within CtBlabeled cells. Data were compared between treatment groups using a $t$ test. Differences were considered significant if $p<0.05$. All values are expressed as means \pm 1 SEM.

Neurophysiology experiments. Anesthesia was induced using a nose cone with isoflurane, and the rats were tracheotomized and pump ventilated (2.5 ml; Rodent Ventilator, model 683; Harvard Apparatus). Isoflurane anesthesia was continued via the ventilator for the duration of surgical preparation ( $3.5 \%$ isoflurane in $50 \% \mathrm{O}_{2}$ ). After surgery was complete, rats were slowly converted to urethane anesthesia $(1.8 \mathrm{~g} / \mathrm{kg})$ via a tail vein catheter. Bilateral vagotomy was performed to eliminate pulmonary stretch-receptor feedback, which entrains respiratory activity with the ventilator. Femoral artery catheterization enabled blood samples to be taken for arterial blood gas analysis. A C2 laminectomy and durotomy were performed to allow placement of one or two intrathecal silicone catheters (2 French; Access Technologies), with their tips located on the dorsal aspect of the $\mathrm{C} 4$ spinal segment. The left phrenic nerve was isolated via dorsal approach, cut distally, desheathed, submerged in mineral oil, and placed on bipolar silver electrodes. After confirming adequate anesthesia (no purposeful movements or cardiorespiratory responses to toe pinch), rats were paralyzed with pancuronium bromide $(2.5 \mathrm{mg} / \mathrm{kg}$, i.v.). Body temperature was measured with a rectal probe (Traceable; Thermo Fisher Scientific) and maintained within $\pm 0.2^{\circ} \mathrm{C}$ of baseline temperature using a custom, temperature-controlled surgical table. End-tidal $\mathrm{CO}_{2}$ was measured with a flow-through capnograph with sufficient response time to measure end-tidal $\mathrm{CO}_{2}$ in rats (Capnogard; Novemetrix), and blood samples were drawn at specified times from the femoral artery into a heparinized, glass syringe $(0.5 \mathrm{ml}$; Hamilton $)$ or heparinized plastic capillary tube $(250 \times 125 \mu \mathrm{l}$ cut in half; Radiometer Medical ApS $)$ to monitor arterial blood gases [partial pressure of arterial oxygen $\left(\mathrm{PaO}_{2}\right)$ and carbon dioxide $\left(\mathrm{PaCO}_{2}\right)$ ], $\mathrm{pH}$, and base excess (ABL 500 or ABL 800Flex; Radiometer Medical ApS). Excess blood was returned to the animal. Blood pressure and acid/base balance were maintained via intravenous infusion of fluids (1:3.75:3 by volume of $1 \mathrm{M} \mathrm{NaHCO} /$ lactated Ringer's solution: $103 \mathrm{~mm} \mathrm{NaCl}, 2 \mathrm{~mm}$ lactate, $4 \mathrm{~mm} \mathrm{KCl}$, and $2 \mathrm{~mm}$ $\mathrm{CaCl} / 6 \%$ Hetastarch; $1.5-2.2 \mathrm{ml} / \mathrm{h}$ ).

Phrenic nerve activity was amplified (10,000×; A-M Systems), bandpass filtered $(100 \mathrm{~Hz}$ to $10 \mathrm{kHz})$, rectified, and processed with a moving averager (time constant of $50 \mathrm{~ms}$; CWE 821 filter; Paynter). The digitized integrated signal was analyzed with WINDAQ data-acquisition system (DATAQ Instruments). Peak integrated phrenic burst amplitude, burst frequency, and mean arterial blood pressure (MAP) were analyzed in $60 \mathrm{~s}$ bins directly before blood samples were taken. Data were included only if $\mathrm{PaO}_{2}>240$ $\mathrm{mmHg}, \mathrm{PaCO}_{2}$ was maintained within $\pm 1.5 \mathrm{mmHg}$ of baseline, base excess was within $\pm 5 \mathrm{mEq} / \mathrm{L}$ of baseline, and the change in MAP from the beginning to the end of a protocol was $<30 \mathrm{mmHg}$. Frequency data and nerve burst amplitudes are expressed as a percentage change from baseline.

At least $1 \mathrm{~h}$ after conversion from isoflurane to urethane anesthesia, the apneic threshold was determined by turning down the inspired $\mathrm{CO}_{2}$ and/or increasing ventilator frequency. Baseline nerve recordings were established by keeping the partial end-tidal $\mathrm{CO}_{2} 1-2 \mathrm{mmHg}$ above the recruitment threshold, the $\mathrm{PaCO}_{2}$ at which respiratory activity resumes after determining the apneic threshold (Bach and Mitchell, 1996). After 25 min of stable nerve recordings, a baseline blood was drawn to establish baseline values to compare subsequent blood gas measurements. The rats then received one of six treatments outlined below. Arterial blood samples were taken 15, 30,60, and 90 min after intrathecal injections. Electrophysiological data were analyzed with repeated-measures, two-way ANOVA (SigmaStat 2.03).

Drug administration. Six treatment protocols were used in the electrophysiological studies: (1) $10 \mu \mathrm{l}$ of VEGFA (recombinant human; $100 \mathrm{ng}$; R \& D Systems) dissolved in $0.1 \% \mathrm{BSA}$ and aCSF (in mM: $120 \mathrm{NaCl}, 3 \mathrm{KCl}, 2 \mathrm{CaCl}, 2$ $\mathrm{MgCl}, 23 \mathrm{NaHCO}_{3}$, and 10 glucose bubbled with $\mathrm{CO}_{2}$ ); (2) $12 \mu \mathrm{l}$ of U0126 [1,4-diamino-2,3-dicyano-1,4-bis(o-aminophenylmercapto)butadiene], a membrane-permeable MEK inhibitor (dissolved in 100\% DMSO and diluted with aCSF to a final concentration of $100 \mathrm{~mm}$ in 20\% DMSO; Promega) before VEGF; (3) U0126 without VEGF; (4) $12 \mu$ l of LY294002, a membrane-permeable phosphotidinositol 3 kinase (PI3K) inhibitor (dissolved in 100\% DMSO and diluted with aCSF to a final concentration of $100 \mathrm{~mm}$ in 20\% DMSO; Tocris Bioscience) before VEGF, (5) LY294002 without VEGF; or (6) just $10 \mu$ l of vehicle (0.1\% BSA in aCSF). All drugs were administered intrathecally over the course of $2 \mathrm{~min}$. In cases in which two drugs were used in the same protocol (e.g., U0126 + VEGF), the inhibitor was given 20 min before the injection of VEGF. When working with VEGF, all syringes, vials, and catheters were incubated beforehand with vehicle to prevent protein binding. The VEGF dose used was chosen based on a preliminary dose-response curve.

\section{Results}

\section{Immunohistochemical experiments}

VEGF and VEGF receptor-2 are expressed in identified phrenic motor neurons

$\mathrm{DAB}$ staining in $\mathrm{C} 4$ ventral horn revealed VEGF protein in putative phrenic motor neurons (Fig. $1 A, B$ ). Using the CtB-backlabeling technique (Mantilla et al., 2009) to localize phrenic motor neurons in naive rats $(n=4)$, we demonstrate that VEGF protein is colocalized within phrenic motor neurons. Photomicrographs of coronal sections of C4 show CtB-positive cells (Fig. 

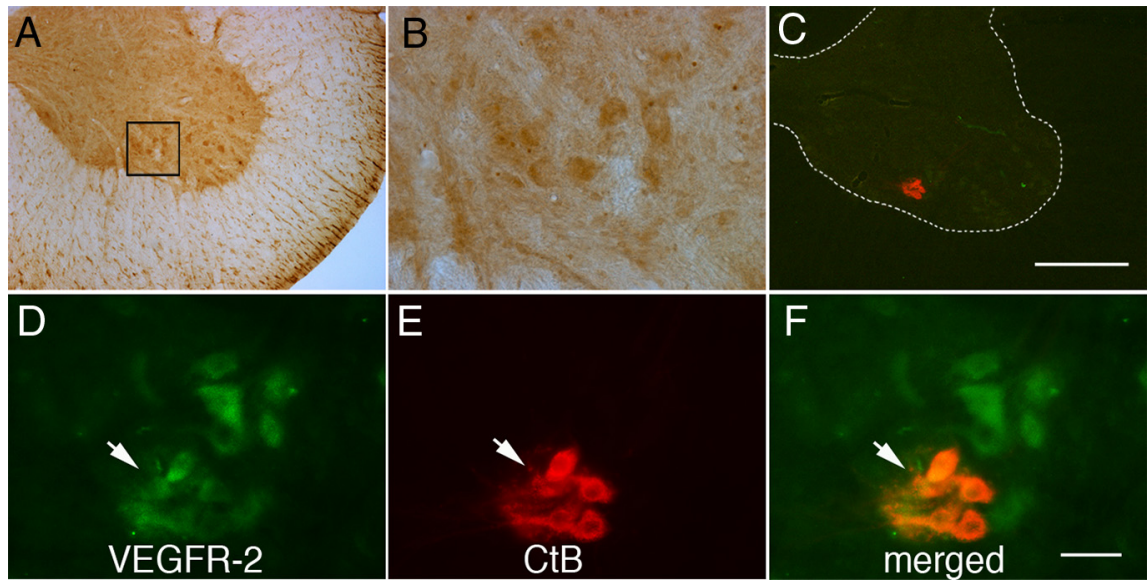

Figure 2. Representative images of VEGF receptor-2 immunostaining in (4 phrenic motor neurons. $A$, DAB staining revealed VEGFR-2 expression in large, presumptive phrenic motor neurons (small black box) and interneurons. $\boldsymbol{B}$, Higher magnification of small black box from $\boldsymbol{A}$. C, Phrenic motor neurons (red cells in ventral horn) were back-labeled with CtB. $\boldsymbol{D}-\boldsymbol{F}$, VEGFR-2 is expressed in phrenic motor neurons (note merged image of red CtB back-labeling and VEGFR-2 protein coexpression) and in nearby unlabeled neurons. Sections incubated without primary or secondary antibodies served as negative controls. Scale bars: $A, C, 400 \mu \mathrm{m} ; \boldsymbol{B}, \boldsymbol{D}-\boldsymbol{F}, 50 \mu \mathrm{m}$.

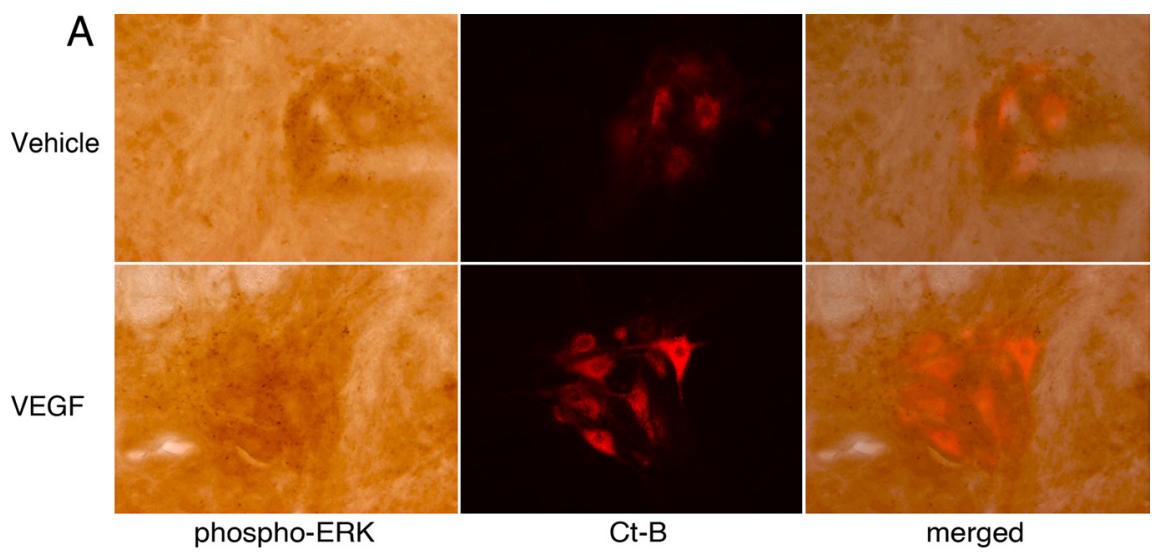

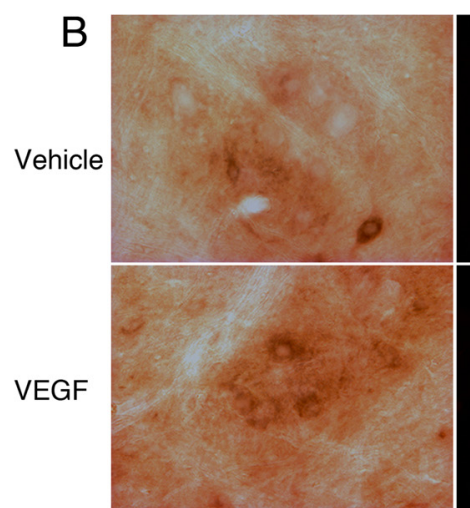

phospho-AKT

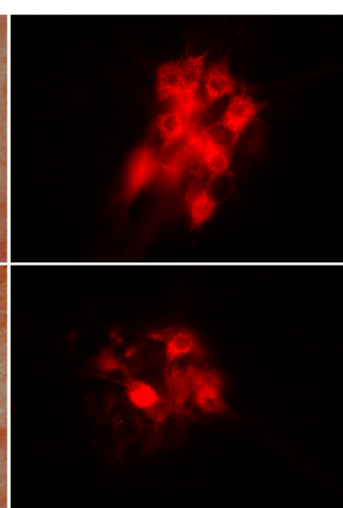

Ct-B

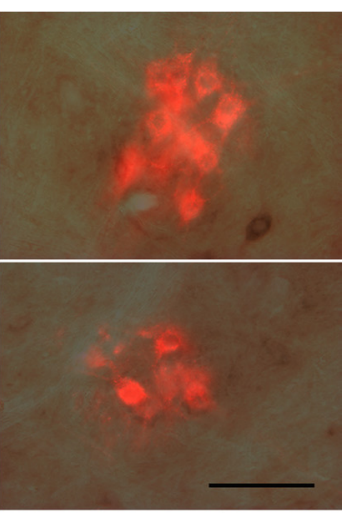

merged
Figure 3. Phospho-ERK and phospho-Akt expression in C4 phrenic motor neurons and upregulation after intrathecal VEGF injection. $A$, Phospho-ERK (far left panels, dark brown staining) is expressed in (4 phrenic motor neurons; staining tends to be punctate and bouton like. $\boldsymbol{B}$, Phospho-Akt protein is colocalized with CtB-back-labeled phrenic motor neurons but appears to have a more dispersed, cytoplasmic distribution (red fluorescence). Both phospho-ERK and phospho-Akt staining increased after intrathecal VEGF injections (see Results). Sections incubated without primary or secondary antibodies served as negative controls. Data are means \pm 1 SEM. ${ }^{*} p<0.05$ versus vehicle. Scale bar, $100 \mu \mathrm{m}$.

$1 C-F)$ in the mediolateral spinal ventral horn in which the phrenic motor neurons are located (Goshgarian and Rafols, 1981; Boulenguez et al., 2007; Mantilla et al., 2009). VEGF immunostaining was also apparent in smaller cells, possibly interneurons (Lane et al., 2008), as well as other non-identified somatic motor neurons (Salhia et al., 2000; Acker et al., 2001). Furthermore, VEGFR-2/KDR, the major VEGFA receptor, is located in putative phrenic motor neurons (Fig. $2 A, B$ ) but also colocalizes with $\mathrm{CtB}$, demonstrating that VEGFR-2 is located within phrenic motor neurons (Fig. $2 C-F)$. Thus, we show for the first time that both VEGF and VEGFR-2 proteins are expressed in phrenic motor neurons.

VEGF increases phospho-ERK and phospho-Akt in phrenic motor neurons Because VEGFR-2 is located in phrenic motor neurons and previous studies demonstrate ERK/mitogen-activated protein kinase and Akt phosphorylation downstream from VEGFR-2 activation, we hypothesized that acute C4 VEGF injections would upregulate phospho-ERK and phospho-Akt in identified phrenic motor neurons. In CtB-labeled phrenic motor neurons, phospho-ERK exhibited punctate, bouton-like immunostaining (Fig. $3 A$, top). This expression was enhanced after VEGF treatment (Fig. 3A, bottom). Densitometric analysis showed a significant VEGF-induced increase in pERK expression $[1.53 \pm 0.13$ vs $1.0 \pm 0.05$ arbitrary units (AU) in controls; $p<$ 0.05]. Phospho-Akt protein was also colocalized with $\mathrm{CtB}$, indicating its presence within phrenic motor neurons (Fig. $3 B$ ). pAkt expression is low within phrenic motor neurons in vehicle-treated rats (Fig. 3B, top). VEGF increased pAkt expression (Fig. 3B, bottom); densitometry revealed that phospho-Akt protein was significantly increased after VEGF treatment $(2.16 \pm 0.41$ vs $1.0 \pm 0.25 \mathrm{AU}$ in controls; $p<0.05)$. Thus, cervical VEGF receptor activation upregulates both phospho-ERK and phospho-Akt expression within identified phrenic motor neurons, although the Akt effect is more robust (116 vs 53\%).

\section{Neurophysiological experiments Regulation of physiological variables under anesthesia}

Variables measured during electrophysiological recordings are shown in Table 1. There were no significant differences among experimental groups in body temperature, blood $\mathrm{pH}$, or base excess values $(p>0.05) \cdot \mathrm{PaO}_{2}$ was maintained above $240 \mathrm{mmHg}$. Mean $\mathrm{PaCO}_{2}$ values did not differ, except for a small, significant 1.0 $\mathrm{mmHg}$ increase between the 15 and 30 min time points in VEGF-treated rats $(p<0.05)$. We do not interpret this small difference as a biologically meaningful change; because $\mathrm{PaCO}_{2}$ was successfully maintained within $1.5 \mathrm{mmHg}$ of baseline values and there were no systematic changes during protocols, changes in phrenic nerve 
Table 1. Body temperature, blood gas values, and MAP for treatment groups

\begin{tabular}{|c|c|c|c|c|c|}
\hline Group & Body temperature & $\mathrm{PaO}_{2}$ & $\mathrm{PaCO}_{2}$ & $\mathrm{pH}$ & MAP \\
\hline \multicolumn{6}{|l|}{ Baseline } \\
\hline $\mathrm{aCSF}+0.1 \% \mathrm{BSA}$ & $37.6 \pm 0.1$ & $266.8 \pm 10.0$ & $45.0 \pm 0.6$ & $7.340 \pm 0.009$ & $121.2 \pm 5.0$ \\
\hline VEGF & $37.6 \pm 0.2$ & $272.2 \pm 8.0$ & $45.4 \pm 0.6$ & $7.344 \pm 0.006$ & $125.0 \pm 5.3$ \\
\hline U0126 + VEGF & $37.5 \pm 0.2$ & $270.2 \pm 8.5$ & $46.3 \pm 0.7$ & $7.338 \pm 0.008$ & $124.7 \pm 3.4$ \\
\hline LY294002 + VEGF & $37.1 \pm 0.2$ & $272.7 \pm 11.2$ & $44.9 \pm 0.9$ & $7.355 \pm 0.006$ & $107.7 \pm 7.0$ \\
\hline \multicolumn{6}{|l|}{$15 \min$} \\
\hline $\mathrm{aCSF}+0.1 \% \mathrm{BSA}$ & $37.6 \pm 0.1$ & $260.8 \pm 10.9$ & $44.6 \pm 0.8$ & $7.342 \pm 0.012$ & $122.9 \pm 3.9$ \\
\hline VEGF & $37.6 \pm 0.2$ & $270.4 \pm 8.7$ & $45.0 \pm 0.5$ & $7.343 \pm 0.007$ & $122.1 \pm 5.0$ \\
\hline U0126 + VEGF & $37.5 \pm 0.2$ & $265.9 \pm 7.9$ & $46.6 \pm 0.4$ & $7.337 \pm 0.008$ & $126.4 \pm 4.2$ \\
\hline LY294002 + VEGF & $37.2 \pm 0.1$ & $259.6 \pm 11.9$ & $44.3 \pm 0.8$ & $7.346 \pm 0.010$ & $96.5 \pm 3.7$ \\
\hline \multicolumn{6}{|l|}{$30 \mathrm{~min}$} \\
\hline $\mathrm{aCSF}+0.1 \% \mathrm{BSA}$ & $37.6 \pm 0.1$ & $259.2 \pm 10.9$ & $44.4 \pm 0.8$ & $7.345 \pm 0.012$ & $122.8 \pm 4.7$ \\
\hline VEGF & $37.5 \pm 0.1$ & $265.2 \pm 9.0$ & $46.0 \pm 0.6^{*}$ & $7.335 \pm 0.007$ & $118.3 \pm 5.5^{* *}$ \\
\hline U0126 + VEGF & $37.4 \pm 0.1$ & $267.5 \pm 7.5$ & $46.7 \pm 0.7$ & $7.337 \pm 0.009$ & $124.2 \pm 4.7$ \\
\hline LY294002 + VEGF & $37.2 \pm 0.1$ & $258.7 \pm 11.9$ & $46.9 \pm 0.7$ & $7.353 \pm 0.010$ & $105.9 \pm 8.5$ \\
\hline \multicolumn{6}{|l|}{$60 \mathrm{~min}$} \\
\hline $\mathrm{aCSF}+0.1 \% \mathrm{BSA}$ & $37.5 \pm 0.2$ & $264.1 \pm 10.1$ & $44.8 \pm 0.8$ & $7.348 \pm 0.012$ & $119.7 \pm 3.9$ \\
\hline VEGF & $37.6 \pm 0.2$ & $264.1 \pm 8.6$ & $46.0 \pm 0.6$ & $7.332 \pm 0.011$ & $113.1 \pm 5.8^{* *}$ \\
\hline U0126 + VEGF & $37.5 \pm 0.1$ & $265.8 \pm 7.3$ & $45.8 \pm 0.5$ & $7.341 \pm 0.011$ & $124.9 \pm 6.1$ \\
\hline LY294002 + VEGF & $37.1 \pm 0.2$ & $273.1 \pm 5.1$ & $45.2 \pm 0.6$ & $7.356 \pm 0.009$ & $105.2 \pm 7.3$ \\
\hline \multicolumn{6}{|l|}{$90 \mathrm{~min}$} \\
\hline $\mathrm{aCSF}+0.1 \% \mathrm{BSA}$ & $37.5 \pm 0.2$ & $268.6 \pm 9.7$ & $44.9 \pm 0.7$ & $7.350 \pm 0.013$ & $117.0 \pm 4.7$ \\
\hline VEGF & $37.5 \pm 0.2$ & $266.7 \pm 9.6$ & $46.0 \pm 0.7$ & $7.332 \pm 0.012$ & $102.6 \pm 9.5^{* *}$ \\
\hline U0126 + VEGF & $37.4 \pm 0.2$ & $265.2 \pm 7.8$ & $45.9 \pm 0.6$ & $7.340 \pm 0.012$ & $121.6 \pm 9.5$ \\
\hline LY294002 + VEGF & $37.1 \pm 0.1$ & $267.8 \pm 9.8$ & $45.2 \pm 0.4$ & $7.353 \pm 0.011$ & $100.4 \pm 8.3$ \\
\hline
\end{tabular}

All values expressed as mean \pm SEM. * indicates significantly different from 15 min time point in VEGF-treated group; ${ }^{* *}$ indicates significantly different from baseline values of VEGF-treated group.

activity cannot be attributed to differences in chemoreceptor feedback.

As noted in previous studies using this same experimental preparation (Baker-Herman and Mitchell, 2008), MAP tends to decrease throughout a protocol. However, rats were excluded from analysis if MAP decreased by $>30 \mathrm{mmHg}$ from baseline values. Although MAP decreased to the same extent in most experimental groups, there was a significantly greater decrease in average MAP over time in the VEGF (see Table 1$)(p<0.05)$ versus LY294002 treatment groups $(n=3 ; p<0.05)$ This difference was sufficiently small that we do not believe it significantly impacted our results (Neverova et al., 2007).

Cervical spinal VEGF elicits $p M F$

Representative traces of phrenic nerve activity before, during, and after VEGF (10 $\mu \mathrm{l}, 100 \mathrm{ng}$ ) or vehicle injections into the C4 intrathecal space are shown in Figure $4 A$, and mean responses are shown in Figure $4 B$. Phrenic burst amplitude was significantly increased from baseline at $15 \mathrm{~min}$ and at all time points thereafter (all $p<0.001 ; n=$ 10 ), indicating the presence of pMF. In contrast, vehicle control rats did not exhibit significant changes in phrenic burst amplitude at any time (all $p>0.05 ; n=9$ ). Changes in phrenic burst amplitude after VEGF injections were significantly greater than in vehicle, control rats after the 15 min time point (all $p<0.003$ ).

\section{Full expression of VEGF-induced pMF requires spinal ERK activation}

To test the hypothesis that VEGF-induced pMF requires spinal ERK activation, rats were pretreated with the potent MEK inhibitor U0126 before VEGF administration. U0126 pretreatment attenuated, but did not abolish, VEGF-induced pMF (Fig. 5A). VEGF still elicits a modest but attenuated increase in phrenic burst amplitude (i.e., pMF) by $60 \mathrm{~min}$ after injection $(25 \pm 8 \%$ baseline; $p<0.006 ; n=7)$. pMF in rats treated with VEGF alone is significantly greater at time points $>60 \mathrm{~min}$ after injection (all $p<0.001)$. Rats treated with U0126 alone exhibited no significant $\mathrm{pMF}$ at any time point $(p>0.05)$ and were not different from vehicle controls $(p>0.05 ; n=3)$.
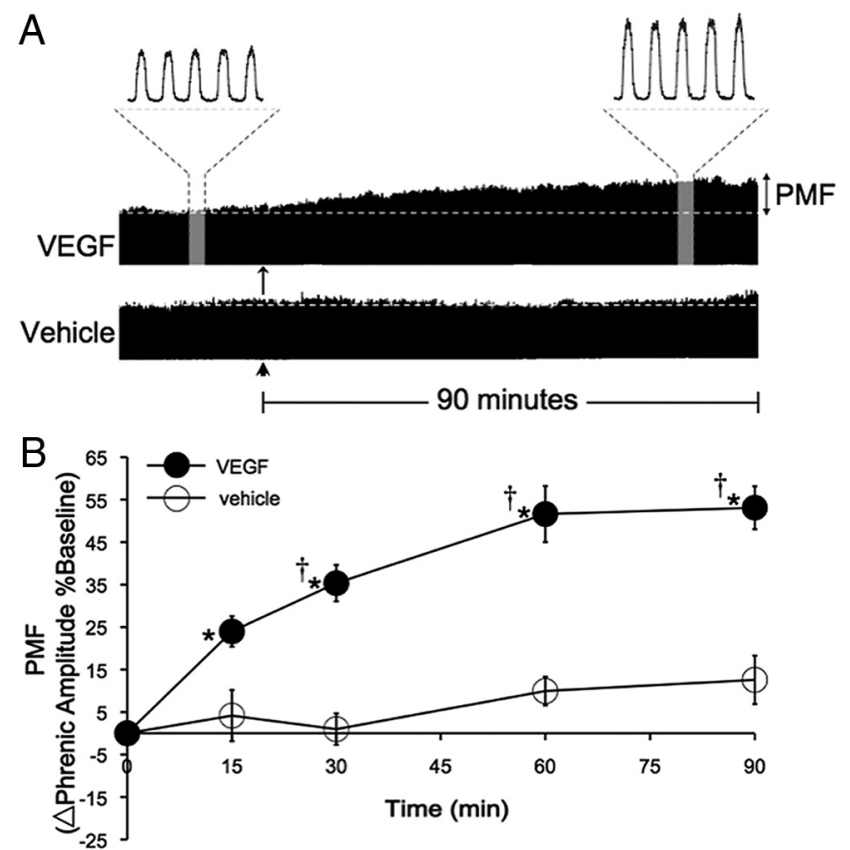

Figure 4. Intrathecal VEGF elicits long-lasting phrenic motor facilitation. $\boldsymbol{A}$, Representative, compressed phrenic neurograms showing either pMF after VEGF injection (arrow) or a lack of facilitation after vehicle injections (aCSF plus bovine serum albumen; arrowhead). $\boldsymbol{B}$, The amplitude of integrated phrenic bursts increases above baseline after injection of $10 \mu \mathrm{l}$ ( $100 \mathrm{ng})$ of VEGF ( $n=10$; filled circles) and is also significantly greater than vehicle controls at the same time point (10 $\mu \mathrm{l} ; n=9$; open circles). All values are expressed as percentage changes in phrenic burst amplitude from baseline. Mean values \pm 1 SEM. ${ }^{*} p<0.001$, significantly different from baseline; ${ }^{\dagger} p<0.003$, significantly different from vehicle at the same time point.

VEGF-induced pMF requires spinal Akt activation

To test the hypothesis that VEGF-induced pMF requires spinal Akt activation, we pretreated rats with the PI3K inhibitor (LY294002) 20 min before VEGF administration. LY294002 pretreatment abolished VEGF-induced pMF at the $60 \mathrm{~min}$ time point, an effect that lasted at least 90 min after VEGF injection $(n=6)$ (Fig. 5B). LY294002 alone had no effect on phrenic burst 

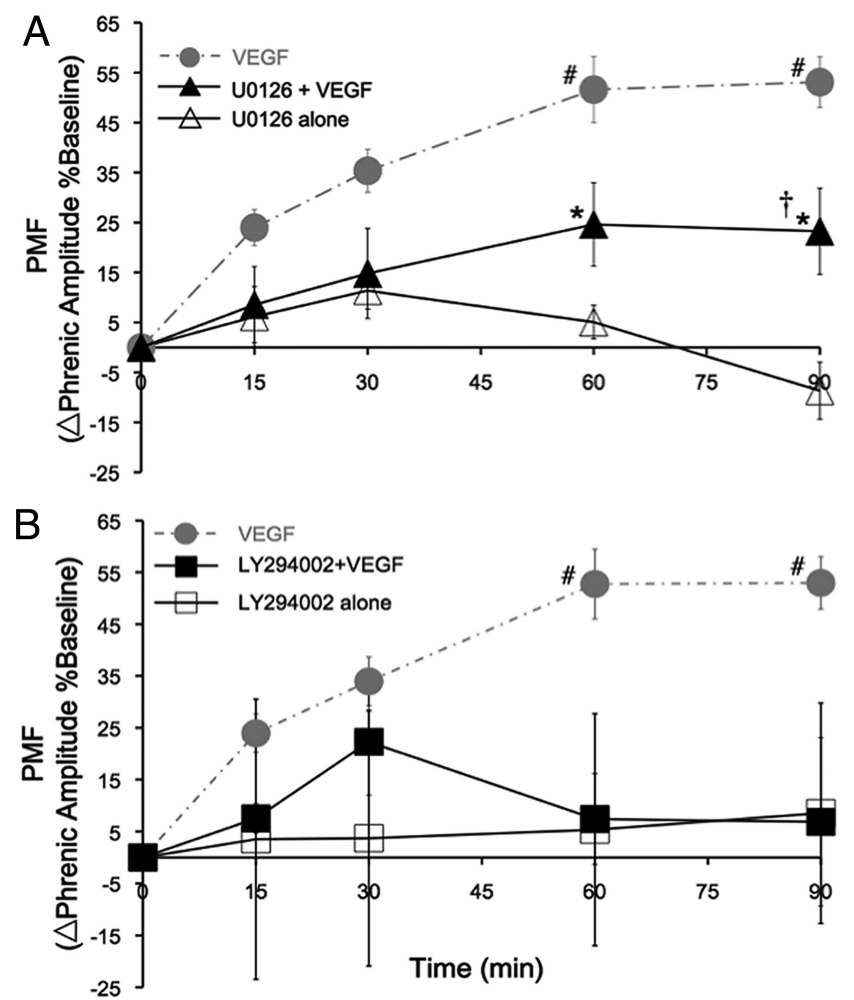

Figure 5. VEGF-induced phrenic motor facilitation requires spinal ERK and Akt activation. $\boldsymbol{A}$, Spinal VEGF elicits pMF (gray dashed line; ${ }^{\#} p<0.001$ indicates significant difference from both U0126 plus VEGF and U0126 alone, $n=10$ ). Pretreatment with the MEK inhibitor U0126 partially blocks VEGF-induced pMF; phrenic amplitude increases versus baseline by $60 \mathrm{~min}$ after injection ( $n=7$; ${ }^{*} p<0.006$ ); however, pMF is attenuated starting 30 min after VEGF (filled triangles; $n=7$ ). U0126 alone had no effect on phrenic motor output versus baseline or vehicle controls at the same time points (open triangles; $n=3$ ); phrenic motor output was significantly lower than U0126 plus VEGF-treated rats ( ${ }^{\dagger} p<0.007$ ) at the 90 min time point. $\boldsymbol{B}$, Gray, dashed line shows VEGF-induced pMF. After pretreatment with the PI3K inhibitor LY294002, pMF is abolished by 60 min after VEGF injection (filled squares; $n=6$ ). LY294002 alone has no effect on phrenic nerve activity (open squares; $n=3$ ). $\# p<0.005$ indicates significant difference in VEGF-injected rats versus those pretreated with inhibitor and versus inhibitor alone (all).

amplitude compared with baseline values or vehicle control experiments $(n=3$; all $p>0.05)$.

Spinal VEGF elicits transient facilitation of phrenic burst frequency VEGF-treated rats showed a slight but significant increase in phrenic burst frequency from 30 to 90 min after injection $(n=$ 10 ; all $p<0.01$ ). Compared with vehicle controls, there was a significant increase in nerve burst frequency midway through the protocol (Fig. $6 A)(p<0.05)$, but that effect was absent by $90 \mathrm{~min}$ after injection. Figure $6, B$ and $C$, illustrates that there were no significant differences (vs baseline or vehicle controls) in frequency for rats treated with U0126 plus VEGF $(n=7 ; p>0.05)$, U0126 alone ( $n=3 ; p>0.05)$, LY294002 plus VEGF $(n=6 ; p>$ $0.05)$, or LY294002 alone $(n=3 ; p>0.05)$. Thus, VEGF-induced frequency facilitation is small ( $\sim 10 \%$ above baseline) and variable (only observed at a few time points). This limited frequency LTF may be attributable to a low baseline frequency in VEGFtreated rats because there is a negative correlation between low baseline frequency and probability of frequency LTF (BakerHerman and Mitchell, 2008).

\section{Discussion}

VEGF, originally described as an angiogenic factor (Connolly et al., 1989), is now known to be neurotrophic and neuroprotective
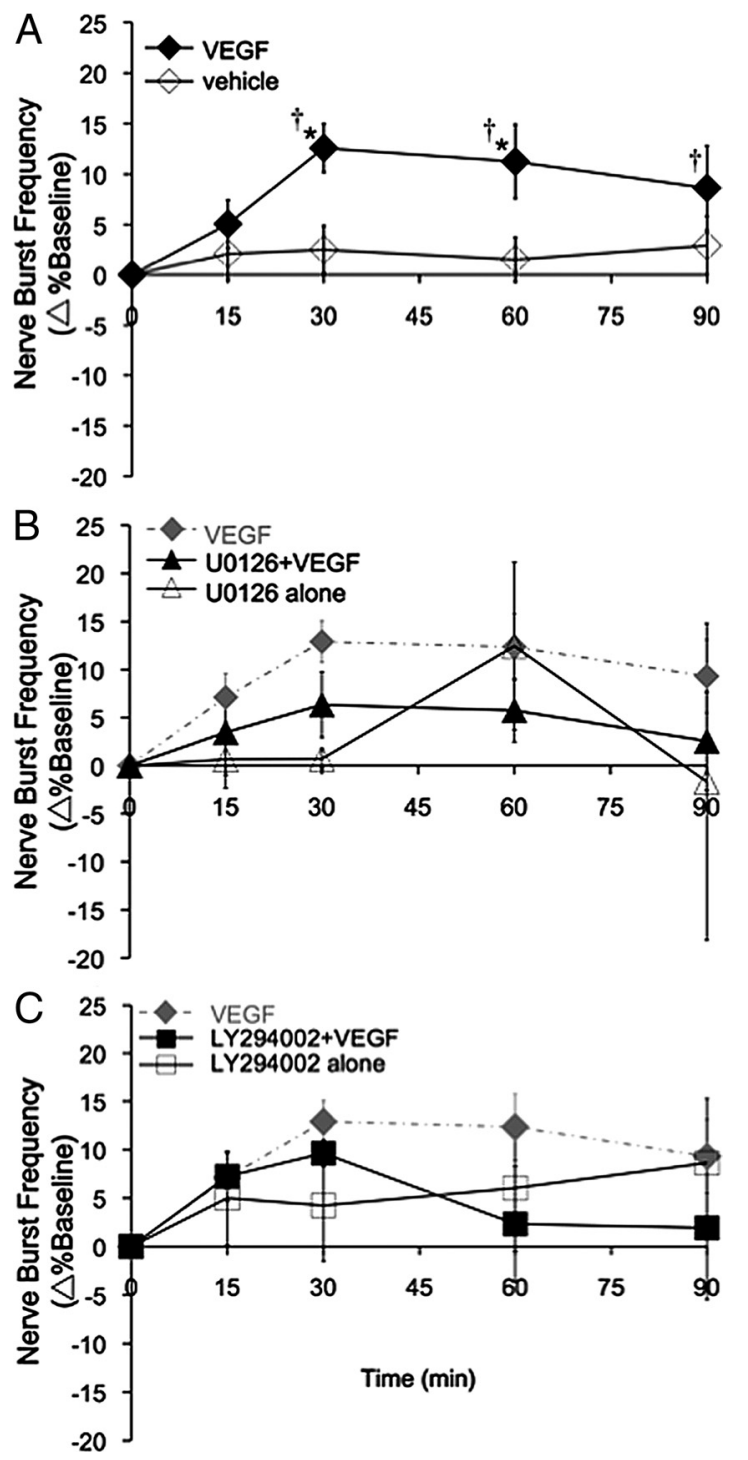

Figure 6. Effects of VEGF administration on phrenic burst frequency. $A$, Intrathecal VEGF elicits a brief facilitation in burst frequency versus baseline values $\left({ }^{\dagger} p<0.01 ; n=10\right)$. Although frequency facilitation is demonstrated at the 30 and 60 min time points, this facilitation is absent by 90 min after VEGF injection ( ${ }^{*} p<0.04$ vs vehicle controls; $n=10$ ). Frequency facilitation is a small and variable phenomenon, and, thus, these results are difficult to interpret. $B, C$, There are no significant increases in nerve burst frequency in any other group (vs baseline; all $p>0.05$ ).

for motor neurons (Storkebaum et al., 2004; Góra-Kupilas and Jośko, 2005; Zachary, 2005). Here, we demonstrate that VEGF also elicits spinal respiratory plasticity. Specifically, (1) VEGFA165 and VEGFR-2 are expressed in identified phrenic motor neurons, (2) cervical spinal VEGF increases phosphorylated ERK and Akt (downstream from VEGFR-2) within phrenic motor neurons, and (3) spinal VEGFR-2 activation with VEGF initiates long-lasting pMF via a mechanism that requires PI3K/Akt and partially requires MEK/ERK activation, which is consistent with predicted actions of VEGFR-2 (Franke et al., 1997; Golder, 2008). Our working cellular/synaptic model of VEGF-induced pMF is shown in Figure 7. Because VEGF expression is induced during prolonged hypoxia via hypoxia inducible factor-1 $\alpha$ (HIF-1 $\alpha$ ) regulation, VEGF within respiratory motor neurons may play a role in hypoxia-induced respiratory plasticity, particularly induced by chronic (days) or repetitive exposure to intermittent hypoxia (Powell et al., 1998; Mitchell and Johnson, 2003; Mahamed and 


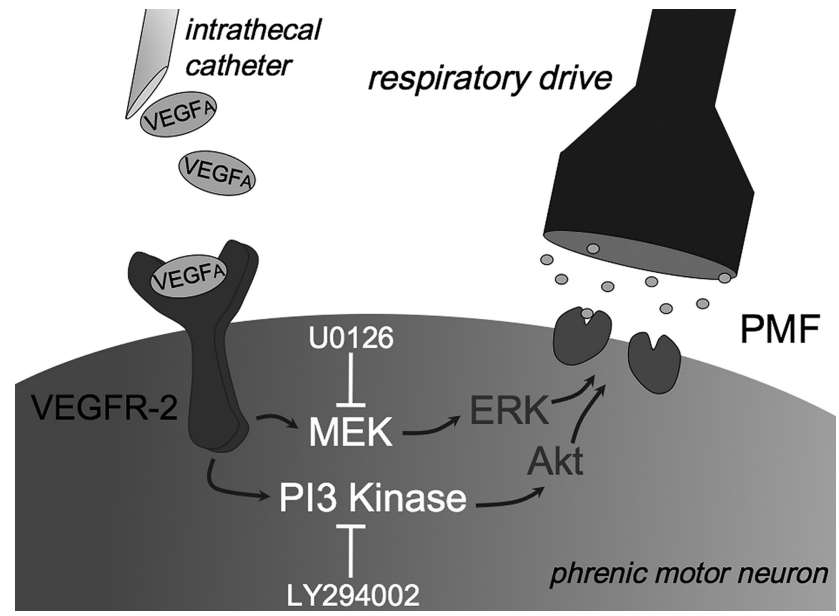

Figure 7. Working model of VEGF-induced pMF. VEGF binds its most common receptor, VEGFR-2, a receptor tyrosine kinase. Downstream signaling includes both MEK/ERK and PI3K/ Akt pathways. These cascades are required for full expression of VEGF-induced pMF because PI3K (LY294002) inhibitors abolish pMF, whereas the MEK inhibitor (U0126) attenuates VEGFinduced pMF. Mechanisms downstream from Akt and ERK are unknown. However, pMF may result from increased glutamate receptor insertion on the postsynaptic membrane between premotor and phrenic motor neurons. pMF may also arise from the ability of phosphorylated ERK to alter membrane excitability, such as changes in sodium channel gating properties that increase the likelihood of phrenic motor neuron firing (Stamboulian et al., 2010).

Mitchell, 2007). VEGF-induced pMF is expected to occur in time domains longer (many hours to days) than those required for BDNF-dependent pLTF after acute intermittent hypoxia (15-30 min cumulative exposure) because hypoxia-induced VEGF expression requires transcriptional regulation via HIF- $1 \alpha$ (Forsythe et al., 1996). VEGF-dependent plasticity could be important in compensating for neurological disorders that lead to respiratory insufficiency, such as cervical spinal injury or motor neuron disease (Mitchell, 2007).

\section{ERK and VEGF-induced pMF}

ERK-1 and ERK-2 (Yu and Sato, 1999) play important roles in synaptic plasticity. ERK is involved in invertebrate memory formation in Aplysia (Martin et al., 1997) and, in mammals, is required for long-term spatial memory formation (Kornhauser and Greenberg, 1997; Blum et al., 1999; Selcher et al., 1999) and fear conditioning (Atkins et al., 1998). ERK phosphorylation also alters gating properties of certain sodium channel subtypes (Stamboulian et al., 2010), making cells more likely to fire, even with weak stimulation. ERK may play a similar role in spinal pMF.

There are several types of pMF, and many occur via mechanisms that converge on ERK and/or Akt phosphorylation (DaleNagle et al., 2010). One form of pMF induced by acute intermittent hypoxia, pLTF (Mitchell et al., 2001), requires BDNF-induced ERK activation (Hoffman and Mitchell, unpublished observation) (Wilkerson and Mitchell, 2009). New BDNF synthesis is necessary and sufficient to elicit pLTF (Baker-Herman et al., 2004). BDNF normally activates ERK and Akt in motor neurons (Gooney and Lynch, 2001; Kishino and Nakayama, 2003); thus, it is somewhat surprising that inhibition of spinal MEK (the kinase that activates ERK) abolishes pLTF (Hoffman and Mitchell, unpublished observation), whereas inhibition of spinal PI3K (which leads to Akt activation) does not (Hoffman and Mitchell, unpublished observation). Repetitive intermittent hypoxia increases ERK phosphorylation in the cervical ventral horn (Wilkerson and Mitchell, 2009). Thus, ERK is a key molecule in respiratory plasticity and appears to play at least some role in VEGF-induced pMF.

\section{Akt and VEGF-induced pMF}

PI3K activity and Akt phosphorylation are also implicated in synaptic plasticity (Franke et al., 1997). PI3K activation is necessary for chemotaxis learning in C. elegans (Tomioka et al., 2006), induction of hippocampal long-term potentiation (Opazo et al., 2003), and fear conditioning in rat prefrontal cortex (Sui et al., 2008). Here we show that the PI3K/Akt pathway is critical for VEGF-induced pMF.

Spinal activation of $\mathrm{G}_{\mathrm{s}}$-protein-coupled metabotropic adenosine $2 \mathrm{~A}$ receptors elicits $\mathrm{pMF}$ via $\mathrm{TrkB}$ trans-activation without new BDNF synthesis (Golder et al., 2008), a pathway associated with increased Akt phosphorylation (Golder et al., 2008). Although the requirement for PI3K/Akt signaling has not been tested for adenosine $2 \mathrm{~A}$ receptor activation-induced $\mathrm{pMF}$, it is necessary for $\mathrm{pMF}$ induced by $5-\mathrm{HT}_{7}$ receptor activation, another $\mathrm{G}_{\mathrm{s}}$-protein-coupled metabotropic receptor (Hoffman and Mitchell, 2011). Thus, there is precedent for both Akt and ERK signaling in different forms of pMF. Here, we demonstrate that Akt activation is necessary for VEGF-induced pMF.

\section{Possible mechanisms of VEGF-induced pMF}

Downstream mechanisms leading to pMF after Akt and ERK activation have not been tested. We postulate that glutamate receptor phosphorylation and/or membrane insertion contribute to enhanced glutamatergic transmission in phrenic motor neurons. NMDA receptor activation is necessary for pLTF in vivo (McGuire et al., 2005, 2008). Furthermore, episodic serotonin administration to hypoglossal motor neurons elicits in vitro LTF and increased AMPA-induced currents (Bocchiaro and Feldman, 2004). VEGF upregulates the GluR2 subunit of AMPA receptors in vivo and in vitro (Bogaert et al., 2010), supporting a mechanism of VEGFinduced synaptic plasticity based on increased postsynaptic AMPA currents. GluR2 upregulation may protect spinal motor neurons from excitotoxicity (Bogaert et al., 2010), suggesting a cellular basis for VEGFinduced neuroprotection in rodent models of ALS (see below).

\section{VEGF-induced frequency facilitation}

After AIH, changes in respiratory activity are primarily expressed in burst amplitude, with small and inconsistent changes in respiratory burst frequency (Baker-Herman and Mitchell, 2008). VEGF elicited a small increase in burst frequency at $30 \mathrm{~min}$ after injection that was gone by $90 \mathrm{~min}$. This transient frequency facilitation may be attributable to VEGF spread to brainstem regions associated with respiratory rhythm generation or to VEGF effects on neurotransmission in spinal sensory afferent pathways that project to the respiratory rhythm generator. However, in a recent meta-analysis of phrenic long-term facilitation after AIH (Baker-Herman and Mitchell, 2008), frequency facilitation was negatively correlated with baseline values. Indeed, baseline frequency before VEGF treatment was arbitrarily lower than vehicle rats (data not shown). Given the small and transient nature of frequency facilitation, we did not explore it further in the present study.

\section{VEGF and hypoxia}

VEGF is regulated by the HIF-1 transcription factor (Semenza, 2009). HIF-1, sometimes regarded as the "master regulator" of cellular oxygen homeostasis, is composed of a constitutively active $\beta$ subunit (HIF-1 $\beta$ ) and an oxygen-regulated $\alpha$ subunit (HIF- $1 \alpha$ ) (Wang et al., 1995). In normoxia, HIF- $1 \alpha$ is ubiquitinated (Kamura et al., 2000; Kaelin and Ratcliffe, 2008) and degraded (Salceda and Caro, 1997) after proline residue hydroxylation. Factor inhibiting HIF-1 (FIH-1) also binds to HIF- $1 \alpha$, hydroxylates asparagine residues, and prevents interaction with cofactors and HIF-1 $\beta$ (Mahon et al., 2001), thus preventing translocation to the nucleus and tran- 
scription. During continuous hypoxia, loss of substrate $\left(\mathrm{O}_{2}\right)$ and/or increased mitochondrial reactive oxygen species (ROS) production inactivates prolyl hydroxylases (PHDs), stabilizing HIF- $1 \alpha$ and enabling dimerization (Kaelin and Ratcliffe, 2008). HIF-1 then binds to the hypoxia response element (HRE) in the promoter of hypoxiasensitive genes and initiates transcription (Forsythe et al., 1996). VEGF upregulation via continuous hypoxia (many hours to days) may contribute to forms of respiratory plasticity such as ventilatory acclimatization to chronic hypoxia (cf. Powell et al., 1998).

During chronic intermittent hypoxia (CIH) (5 min episodes lasting several days), HIF- $1 \alpha$ stabilization is more robust. $\mathrm{CIH}$ stimulates $\mathrm{NADPH}$ oxidase-dependent ROS formation and PKC activation in PC12 cell cultures (Yuan et al., 2005, 2008). PKC inhibits PHD activity (stabilizing the HIF-1 complex) and induces mammalian target of rapamycin-dependent synthesis of new HIF- $1 \alpha$, enabling longer-lasting stabilization of HIF-1 and greater VEGF expression (Yuan et al., 2005, 2008). Thus, VEGF is likely to play an important role in forms of spinal respiratory plasticity induced by CIH (Mitchell and Johnson, 2003; Mahamed and Mitchell, 2007).

In contrast to $\mathrm{CIH}$, acute intermittent hypoxia elicits pLTF, a unique form of respiratory plasticity that requires new BDNF synthesis (via translation of existing mRNA) and TrkB activation (Baker-Herman et al., 2004). We do not envision a role for VEGF in pLTF because the timeframe is too short to involve transcriptional regulation of gene expression $(<1 \mathrm{~h})$. However, when rats are subjected to repetitive intermittent hypoxia over several days, pLTF is enhanced, revealing respiratory metaplasticity (Ling et al., 2001; Wilkerson and Mitchell, 2009). Because VEGF protein is upregulated within phrenic motor neurons after repetitive intermittent hypoxia (our unpublished observations), it may play a role in respiratory plasticity and/or metaplasticity after repetitive or prolonged exposure to intermittent hypoxia. Additional study of this possibility is warranted.

\section{VEGF and ALS}

Mice lacking the ability to upregulate VEGF during hypoxia develop motor neuron degeneration (Oosthuyse et al., 2001). In ALS patients, CSF VEGF is decreased (Moreau et al., 2009, 2010). Thus, VEGF administration to the CNS in rodent models of ALS decreases the rate of motor neuron degeneration, improves motor performance, and delays disease progression (Storkebaum et al., 2004; Van Den Bosch et al., 2004; Zheng et al., 2004; Vande Velde and Cleveland, 2005; Tovar-Y-Romo et al., 2007; Wang et al., 2007; Hwang et al., 2009; Lunn et al., 2009). VEGF may be of benefit during motor neuron disease as a result of diminished excitotoxic cell death (Bogaert et al., 2010) via a PI3K-dependent mechanism (Tolosa et al., 2008), reduced astroglial activation, or preservation of neuromuscular junctions (Zheng et al., 2007). Based on the present study, we suggest that an unrecognized benefit of VEGF treatments may be improved respiratory (and somatic) motor function as a result of mechanisms of induced compensatory plasticity. This effect may be of considerable importance because ventilatory failure is the most frequent cause of death in ALS.

\section{References}

Acker T, Beck H, Plate KH (2001) Cell type specific expression of vascular endothelial growth factor and angiopoietin-1 and -2 suggests an important role of astrocytes in cerebellar vascularization. Mech Dev 108:45-57.

Atkins CM, Selcher JC, Petraitis JJ, Trzaskos JM, Sweatt JD (1998) The MAPK cascade is required for mammalian associative learning. Nat Neurosci 1:602-609.

Bach KB, Mitchell GS (1996) Hypoxia-induced long-term facilitation of respiratory activity is serotonin dependent. Respir Physiol 104:251-260.

Baker-Herman TL, Mitchell GS (2008) Determinants of frequency long- term facilitation following acute intermittent hypoxia in vagotomized rats. Respir Physiol Neurobiol 162:8-17.

Baker-Herman TL, Fuller DD, Bavis RW, Zabka AG, Golder FJ, Doperalski NJ, Johnson RA, Watters JJ, Mitchell GS (2004) BDNF is necessary and sufficient for spinal respiratory plasticity following intermittent hypoxia. Nat Neurosci 7:48-55.

Blum S, Moore AN, Adams F, Dash PK (1999) A mitogen-activated protein kinase cascade in the CA1/CA2 subfield of the dorsal hippocampus is essential for long-term spatial memory. J Neurosci 19:3535-3544.

Bocchiaro CM, Feldman JL (2004) Synaptic activity-independent persistent plasticity in endogenously active mammalian motoneurons. Proc Natl Acad Sci U S A 101:4292-4295.

Bogaert E, Van Damme P, Poesen K, Dhondt J, Hersmus N, Kiraly D, Scheveneels W, Robberecht W, Van Den Bosch L (2010) VEGF protects motor neurons against excitotoxicity by upregulation of GluR2. Neurobiol Aging 31:2185-2191.

Boulenguez P, Gestreau C, Vinit S, Stamegna JC, Kastner A, Gauthier P (2007) Specific and artefactual labeling in the rat spinal cord and medulla after injection of monosynaptic retrograde tracers into the diaphragm. Neurosci Lett 417:206-211.

Castilla MA, Neria F, Renedo G, Pereira DS, González-Pacheco FR, Jiménez S, Tramón P, Deudero JJ, Arroyo MV, Yagüe S, Caramelo C (2004) Tumoinduced endothelial cell activation: role of vascular endothelial growth factor. Am J Physiol Cell Physiol 286:C1170-C1176.

Connolly DT, Heuvelman DM, Nelson R, Olander JV, Eppley BL, Delfino JJ, Siegel NR, Leimgruber RM, Feder J (1989) Tumor vascular permeability factor stimulates endothelial cell growth and angiogenesis. J Clin Invest 84:1470-1478.

Dale-Nagle EA, Hoffman MS, MacFarlane PM, Mitchell GS (2010) Multiple pathways to long-lasting phrenic motor facilitation. Adv Exp Med Biol 669:225-230.

Forsythe JA, Jiang BH, Iyer NV, Agani F, Leung SW, Koos RD, Semenza GL (1996) Activation of vascular endothelial growth factor gene transcription by hypoxia-inducible factor 1. Mol Cell Biol 16:4604-4613.

Franke TF, Kaplan DR, Cantley LC (1997) PI3K: downstream AKTion blocks apoptosis. Cell 88:435-437.

Golder FJ (2008) Receptor tyrosine kinases and respiratory motor plasticity. Respir Physiol Neurobiol 164:242-251.

Golder FJ, Ranganathan L, Satriotomo I, Hoffman M, Lovett-Barr MR, Watters JJ, Baker-Herman TL, Mitchell GS (2008) Spinal adenosine A2a receptor activation elicits long-lasting phrenic motor facilitation. J Neurosci 28:2033-2042.

Gooney M, Lynch MA (2001) Long-term potentiation in the dentate gyrus of the rat hippocampus is accompanied by brain-derived neurotrophic factor-induced activation of TrkB. J Neurochem 77:1198-1207.

Góra-Kupilas K, Jośko J (2005) The neuroprotective function of vascular endothelial growth factor (VEGF). Folia Neuropathol 43:31-39.

Goshgarian HG, Rafols JA (1981) The phrenic nucleus of the albino rat: a correlative HRP and Golgi study. J Comp Neurol 201:441-456.

Hayashi T, Sakurai M, Abe K, Sadahiro M, Tabayashi K, Itoyama Y (1999) Expression of angiogenic factors in rabbit spinal cord after transient ischaemia. Neuropathol Appl Neurobiol 25:63-71.

Hoffman MS, Mitchell GS (2011) Spinal 5-HT receptor activation induces long-lasting phrenic motor facilitation. J Physiol 589:1397-1407.

Hwang DH, Lee HJ, Park IH, Seok JI, Kim BG, Joo IS, Kim SU (2009) Intrathecal transplantation of human neural stem cells overexpressing VEGF provide behavioral improvement, disease onset delay and survival extension in transgenic ALS mice. Gene Ther 16:1234-1244.

Kaelin WG Jr, Ratcliffe PJ (2008) Oxygen sensing by metazoans: the central role of the HIF hydroxylase pathway. Mol Cell 30:393-402.

Kamura T, Sato S, Iwai K, Czyzyk-Krzeska M, Conaway RC, Conaway JW (2000) Activation of HIF-1 $\alpha$ ubiquitination by a reconstituted von Hippel-Lindau (VHL) tumor suppressor complex. Proc Natl Acad Sci U S A 97:10430-10435.

Kishino A, Nakayama C (2003) Enhancement of BDNF and activated-ERK immunoreactivity in spinal motor neurons after peripheral administration of BDNF. Brain Res 964:56-66.

Kornhauser JM, Greenberg ME (1997) A kinase to remember: dual roles for MAP kinase in long-term memory. Neuron 18:839-842.

Lane MA, White TE, Coutts MA, Jones AL, Sandhu MS, Bloom DC, Bolser DC, Yates BJ, Fuller DD, Reier PJ (2008) Cervical prephrenic interneurons in the normal and lesioned spinal cord of the adult rat. J Comp Neurol 511:692-709. 
Ling L, Fuller DD, Bach KB, Kinkead R, Olson EB Jr, Mitchell GS (2001) Chronic intermittent hypoxia elicits serotonin-dependent plasticity in the central neural control of breathing. J Neurosci 21:5381-5388.

Lunn JS, Sakowski SA, Kim B, Rosenberg AA, Feldman EL (2009) Vascular endothelial growth factor prevents G93A-SOD1-induced motor neuron degeneration. Dev Neurobiol 69:871-884.

Mahamed S, Mitchell GS (2007) Is there a link between intermittent hypoxiainduced respiratory plasticity and obstructive sleep apnoea? Exp Physiol 92:27-37.

Mahon PC, Hirota K, Semenza GL (2001) FIH-1: a novel protein that interacts with HIF- $1 \alpha$ and VHL to mediate repression of HIF-1 transcriptional activity. Genes Dev 15:2675-2686.

Mantilla CB, Zhan WZ, Sieck GC (2009) Retrograde labeling of phrenic motoneurons by intrapleural injection. J Neurosci Methods 182:244-249.

Martin KC, Michael D, Rose JC, Barad M, Casadio A, Zhu H, Kandel ER (1997) MAP kinase translocates into the nucleus of the presynaptic cell and is required for long-term facilitation in Aplysia. Neuron 18:899-912.

McGuire M, Zhang Y, White DP, Ling L (2005) Phrenic long-term facilitation requires NMDA receptors in the phrenic motonucleus in rats. J Physiol 567:599-611.

McGuire M, Liu C, Cao Y, Ling L (2008) Formation and maintenance of ventilatory long-term facilitation require NMDA but not non-NMDA receptors in awake rats. J Appl Physiol 105:942-950.

Mitchell GS (2007) Respiratory plasticity following intermittent hypoxia: a guide for novel therapeutic approaches to ventilatory control disorders. In: Genetic basis for respiratory control disorders (Gaultier C, ed). New York: Springer.

Mitchell GS, Johnson SM (2003) Neuroplasticity in respiratory motor control. J Appl Physiol 94:358-374.

Mitchell GS, Baker TL, Nanda SA, Fuller DD, Zabka AG, Hodgeman BA, Bavis RW, Mack KJ, Olson EB Jr (2001) Invited review: intermittent hypoxia and respiratory plasticity. J Appl Physiol 90:2466-2475.

Moreau C, Gosset P, Brunaud-Danel V, Lassalle P, Degonne B, Destee A, Defebvre L, Devos D (2009) CSF profiles of angiogenic and inflammatory factors depend on the respiratory status of ALS patients. Amyotroph Lateral Scler 10:175-181.

Moreau C, Devos D, Gosset P, Brunaud-Danel V, Tonnel AB, Lassalle P, Defebvre L, Destee A (2010) Mechanisms of deregulated response to hypoxia in sporadic amyotrophic lateral sclerosis: a clinical study. Rev Neurol (Paris) 166:279-283.

Neverova NV, Saywell SA, Nashold LJ, Mitchell GS, Feldman JL (2007) Episodic stimulation of alphal-adrenoreceptors induces protein kinase C-persistent changes in motoneuronal excitability. J Neurosci 27: $4435-4442$.

Oosthuyse B, Moons L, Storkebaum E, Beck H, Nuyens D, Brusselmans K, Van Dorpe J, Hellings P, Gorselink M, Heymans S, Theilmeier G, Dewerchin M, Laudenbach V, Vermylen P, Raat H, Acker T, Vleminckx V, Van Den Bosch L, Cashman N, Fujisawa H, et al. (2001) Deletion of the hypoxia-response element in the vascular endothelial growth factor promoter causes motor neuron degeneration. Nat Genet 28:131-138.

Opazo P, Watabe AM, Grant SG, O’Dell TJ (2003) Phosphatidylinositol 3-kinase regulates the induction of long-term potentiation through extracellular signal-related kinase-independent mechanisms. J Neurosci 23: $3679-3688$.

Powell FL, Milsom WK, Mitchell GS (1998) Time domains of the hypoxic ventilatory response. Respir Physiol 112:123-134.

Reichardt LF (2006) Neurotrophin-regulated signaling pathways. Philos Trans R Soc Lond B Biol Sci 361:1545-1564.

Robinson CJ, Stringer SE (2001) The splice variants of vascular endothelial growth factor (VEGF) and their receptors. J Cell Sci 114:853-865.

Sakao S, Taraseviciene-Stewart L, Cool CD, Tada Y, Kasahara Y, Kurosu K, Tanabe N, Takiguchi Y, Tatsumi K, Kuriyama T, Voelkel NF (2007) VEGF-R blockade causes endothelial cell apoptosis, expansion of surviving CD34+ precursor cells and transdifferentiation to smooth musclelike and neuronal-like cells. FASEB J 21:3640-3652.

Salceda S, Caro J (1997) Hypoxia-inducible factor $1 \alpha$ (HIF-1 $\alpha$ ) protein is rapidly degraded by the ubiquitin-proteasome system under normoxic conditions. Its stabilization by hypoxia depends on redox-induced changes. J Biol Chem 272:22642-22647.

Salhia B, Angelov L, Roncari L, Wu X, Shannon P, Guha A (2000) Expression of vascular endothelial growth factor by reactive astrocytes and associated neoangiogenesis. Brain Res 883:87-97.
Selcher JC, Atkins CM, Trzaskos JM, Paylor R, Sweatt JD (1999) A necessity for MAP kinase activation in mammalian spatial learning. Learn Mem 6:478-490.

Semenza GL (2009) Regulation of oxygen homeostasis by hypoxiainducible factor 1. Physiology (Bethesda) 24:97-106.

Senger DR, Perruzzi CA, Feder J, Dvorak HF (1986) A highly conserved vascular permeability factor secreted by a variety of human and rodent tumor cell lines. Cancer Res 46:5629-5632.

Smadja DM, Bièche I, Helley D, Laurendeau I, Simonin G, Muller L, Aiach M, Gaussem P (2007) Increased VEGFR2 expression during human late endothelial progenitor cells expansion enhances in vitro angiogenesis with up-regulation of integrin alpha (6). J Cell Mol Med 11:1149-1161.

Stamboulian S, Choi JS, Ahn HS, Chang YW, Tyrrell L, Black JA, Waxman SG, Dib-Hajj SD (2010) ERK1/2 mitogen-activated protein kinase phosphorylates sodium channel Nav1.7 and alters its gating properties. J Neurosci 30:1637-1647.

Storkebaum E, Lambrechts D, Carmeliet P (2004) VEGF: once regarded as a specific angiogenic factor, now implicated in neuroprotection. Bioessays 26:943-954.

Sui L, Wang J, Li BM (2008) Role of the phosphoinositide 3-kinase-Aktmammalian target of the rapamycin signaling pathway in long-term potentiation and trace fear conditioning memory in rat medial prefrontal cortex. Learn Mem 15:762-776.

Tolosa L, Mir M, Asensio VJ, Olmos G, Lladó J (2008) Vascular endothelial growth factor protects spinal cord motoneurons against glutamate-induced excitotoxicity via phosphatidylinositol 3-kinase. J Neurochem 105:1080-1090.

Tomioka M, Adachi T, Suzuki H, Kunitomo H, Schafer WR, Iino Y (2006) The insulin/PI 3-kinase pathway regulates salt chemotaxis learning in Caenorhabditis elegans. Neuron 51:613-625.

Tovar-Y-Romo LB, Zepeda A, Tapia R (2007) Vascular endothelial growth factor prevents paralysis and motoneuron death in a rat model of excitotoxic spinal cord neurodegeneration. J Neuropathol Exp Neurol 66: 913-922.

Van Den Bosch L, Storkebaum E, Vleminckx V, Moons L, Vanopdenbosch L, Scheveneels W, Carmeliet P, Robberecht W (2004) Effects of vascular endothelial growth factor (VEGF) on motor neuron degeneration. Neurobiol Dis 17:21-28.

Vande Velde C, Cleveland DW (2005) VEGF: multitasking in ALS. Nat Neurosci 8:5-7.

Wang GL, Jiang BH, Rue EA, Semenza GL (1995) Hypoxia-inducible factor 1 is a basic-helix-loop-helix-PAS heterodimer regulated by cellular $\mathrm{O} 2$ tension. Proc Natl Acad Sci U S A 92:5510-5514.

Wang Y, Mao XO, Xie L, Banwait S, Marti HH, Greenberg DA, Jin K (2007) Vascular endothelial growth factor overexpression delays neurodegeneration and prolongs survival in amyotrophic lateral sclerosis mice. J Neurosci 27:304-307.

Wilkerson JE, Mitchell GS (2009) Daily intermittent hypoxia augments spinal BDNF levels, ERK phosphorylation and respiratory long-term facilitation. Exp Neurol 217:116-123.

Yamashita S (2007) Heat-induced antigen retrieval: mechanisms and application to histochemistry. Prog Histochem Cytochem 41:141-200.

Yu Y, Sato JD (1999) MAP kinases, phosphatidinositol 3-kinase, and p70 S6 kinase mediate the mitogenic response of human endothelial cells to vascular endothelial growth factor. J Cell Physiol 178:235-246.

Yuan G, Nanduri J, Bhasker CR, Semenza GL, Prabhakar NR (2005) $\mathrm{Ca}^{2+} /$ calmodulin kinase-dependent activation of hypoxia inducible factor 1 transcriptional activity in cells subjected to intermittent hypoxia. J Biol Chem 280:4321-4328.

Yuan G, Nanduri J, Khan S, Semenza GL, Prabhakar NR (2008) Induction of HIF- $1 \alpha$ expression by intermittent hypoxia: involvement of NADPH oxidase, $\mathrm{CA}^{2+}$ signaling, prolyl hydroxylases and mTOR. J Cell Physiol 217:674-685.

Zachary I (2003) VEGF signaling: integration and multi-tasking in endothelial cell biology. Biochem Soc Trans 31:1171-1177.

Zachary I (2005) Neuroprotective role of vascular endothelial growth factor: signaling mechanisms, biological function, and therapeutic potential. Neurosignals 14:207-221.

Zheng C, Nennesmo I, Fadeel B, Henter JI (2004) Vascular endothelial growth factor prolongs survival in a transgenic mouse model of ALS. Ann Neurol 56:564-567.

Zheng C, Sköld MK, Li J, Nennesmo I, Fadeel B, Henter JI (2007) VEGF reduces astrogliosis and preserves neuromuscular junctions in ALS transgenic mice. Biochem Biophys Res Commun 363:989-993. 